\title{
Biochemical and Physiological Processes in Brain Function and Drug Actions
}

\author{
W. D. Horst ${ }^{1}$ \\ ${ }^{1}$ Psychiatric Research Institute, Suite 200, 1100 N. St. Francis, Wichita, KS 67214, USA \\ e-mail: Dale_horst@via-christi.org
}

1 The Needle in the Haystack. . . . . . . . . . . . . . . . 4

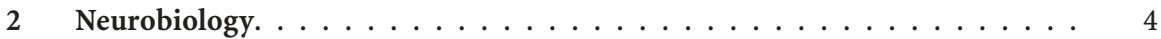

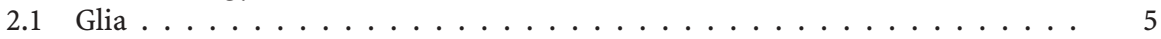

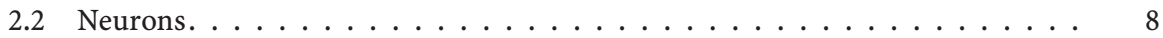

2.3 The Electrical Nature of Neurons. . . . . . . . . . . . . . . . . . 8

2.4 The Synapse . . . . . . . . . . . . . . . . . . . . . . . . 9

2.5 Chemical Transmission . . . . . . . . . . . . . . . . . . . . 10

2.5.1 Neurotransmitter Synthesis . . . . . . . . . . . . . . . . . . . . . 11

2.5.2 Neurotransmitter Storage and Release . . . . . . . . . . . . . . . . . . . 12

2.5.3 Neurotransmitter Inactivation . . . . . . . . . . . . . . . . . . . . . 13

2.5 .4 Receptors . . . . . . . . . . . . . . . . . . . . . . . 17

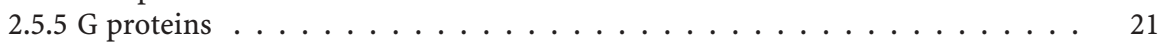

2.5 .6 Second Messengers . . . . . . . . . . . . . . . . 23

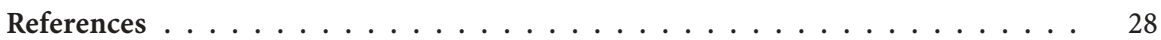

Abstract An understanding of the basic elements of neurotransmission in the brain is an important foundation for any consideration of the clinical use and future development of antidepressants. However, attempts to describe the influences of drugs on brain and neuronal function have become increasingly complex, and it is now clear that neuronal processes are complex molecular events involving multiple control factors. The brain consists of approximately 100 million neurons, which account for half of the brain's volume, with the other half being made up of glial cells. New insights into the function of glial cells, the influence of phosphorylation on neuronal functions, and the regulation of genetic functions in synthesizing neuronal proteins have enhanced our appreciation of the complexity of neural function in the brain. Glial cells play an important role in recycling and conserving the neurotransmitters glutamate and GABA and also have an important effect on neurons in the brain via glial cell line-derived neurotrophic factor (GDNF). The basic function of neurons is to convey electrical signals in a highly organized and integrated way. The dominant means of neuron-to-neuron communication or transmission occurs by means of specific chemicals (i.e., neurotransmitters). Neuronal communication is a complex process that involves neurotransmitter storage and release, neurotransmitter inacti- 
vation, receptors, G proteins, and second messengers. A number of neuronal mechanisms have been identified that are thought to play important roles in the etiology of major depressive disorder (e.g., the serotonin transporter mechanism); an increasing understanding of the neuronal mechanisms that underlie psychiatric disorders will help to guide future drug development.

Keywords Neurotransmitters · Glial cells $\cdot$ Neurons $\cdot$ Synapse $\cdot$ Glial cell line-derived neurotrophic factor $(\mathrm{GDNF}) \cdot \mathrm{G}$ proteins $\cdot$ Second messengers

1

\section{The Needle in the Haystack}

From relatively simple beginnings a half century ago, our attempts to describe drug influences on the brain and neuronal functions have become quite complex. Whereas we once spoke of drugs blocking neurotransmitter uptake, causing neurotransmitter release or depletion, or influencing receptors, today we understand that all of these basic neuronal processes are, in reality, complex molecular events that involve multiple control factors. Identifying a specific molecular mechanism in a drug's action on neuronal functions is, in fact, very much like a search for a needle in a haystack.

New insights concerning glial functions, the influence of phosphorylation on neuronal functions, and, most recently, the regulation of genetic functions in synthesizing neuronal proteins, have significantly enhanced our appreciation of the complexity of neural functions in the brain. As our understanding of basic neuronal and synaptic processes increases, so does the number of potential sites or mechanisms for the expression of depressive behavior and for drug actions. The needle is still only a needle, but the haystack continues to grow larger.

This chapter summarizes and describes our understanding of the basic elements of neurotransmission in the brain and provides a foundation for subsequent discussions of the clinical use and future development of antidepressants.

2

\section{Neurobiology}

The brain consists of approximately 100 million neurons, which account for one half of the brain's volume, the other half being made up of glial cells. Glial cells guide the synaptic formation of neurons during brain development (Bacci et al. 1999), influence the extracellular environment of the neurons (Zahs 1998), synthesize neurotransmitter precursors (Martin 1992), and respond to, or in some cases, may cause brain damage (McGeer and McGeer 1998; Aschner et al. 1999; Raivich et al. 1999). In turn, neurons are known to produce factors that influence the development and function of glia (Melcangi et al. 1999; Vardimon et al. 1999). 
2.1

Glia

For many years, glia were thought to have a somewhat limited or passive role in brain function, but more recent findings indicate that glia have receptors, uptake mechanisms, and enzymes for several neurotransmitters, suggesting that the functions of these cells are closely integrated with neuronal functions (Martin 1992; Ransom and Sontheimer 1992; Attwell1994; Inagaki and Wada 1994; Otero and Merrill 1994) (Table 1).

An important example of this type of interaction is shown in Fig. 1. Glutamate and gamma aminobutyric acid (GABA) are ubiquitous neurotransmitters in brain, serving as primary excitatory and inhibitory neurotransmitters. Glial cells (astrocytes) play a prominent role in recycling and conserving both glutamate and GABA by recapturing them from the synapse, converting them to glutamine, and then returning glutamine to the presynaptic neurons for conversion back to the appropriate transmitter. In addition to the conservation of transmitter, glia protect neurons by limiting synaptic levels of glutamate (Bacci et al. 1999; Vardimon et al. 1999). Prominent among glutamate's several cellular influences is the opening of specific calcium channels that allow the influx of calcium ions into neurons. The overstimulation of neurons via this mechanism has been

Table 1 Membrane elements of mammalian glia (from Ransom and Sontheimer 1992; Sontheimer 1994)

\begin{tabular}{ll}
\hline Receptors $^{\text {a }}$ & Response mode \\
\hline Noradrenergic ( $\alpha$ and $\beta$ ) & G protein \\
Adenosine & G protein \\
Acetylcholine (muscarinic) & G protein \\
Neuropeptides (substance P) & G protein \\
Glutamate (quisqualate, kainate) & lon gating \\
Gamma aminobutyric acid (GABA A) & lon gating \\
lon channels (voltage-sensitive) & \\
Potassium & \\
Inwardly rectifying & \\
Outwardly rectifying & \\
Transient A-type & \\
Sodium & \\
Tetrodotoxin-sensitive-"neuronal" & \\
Tetrodotoxin-resistant-" glial" & \\
Calcium (L and T types) & \\
Chloride & \\
Transporters (uptake sites) & \\
GABA & \\
Glutamate & \\
Glycine & \\
\hline
\end{tabular}

${ }^{a}$ Although nearly all neuronal-type neuroreceptors have been shown to occur on glial membranes, only those that have been shown to produce a response are included here. 


\section{Extracellular}

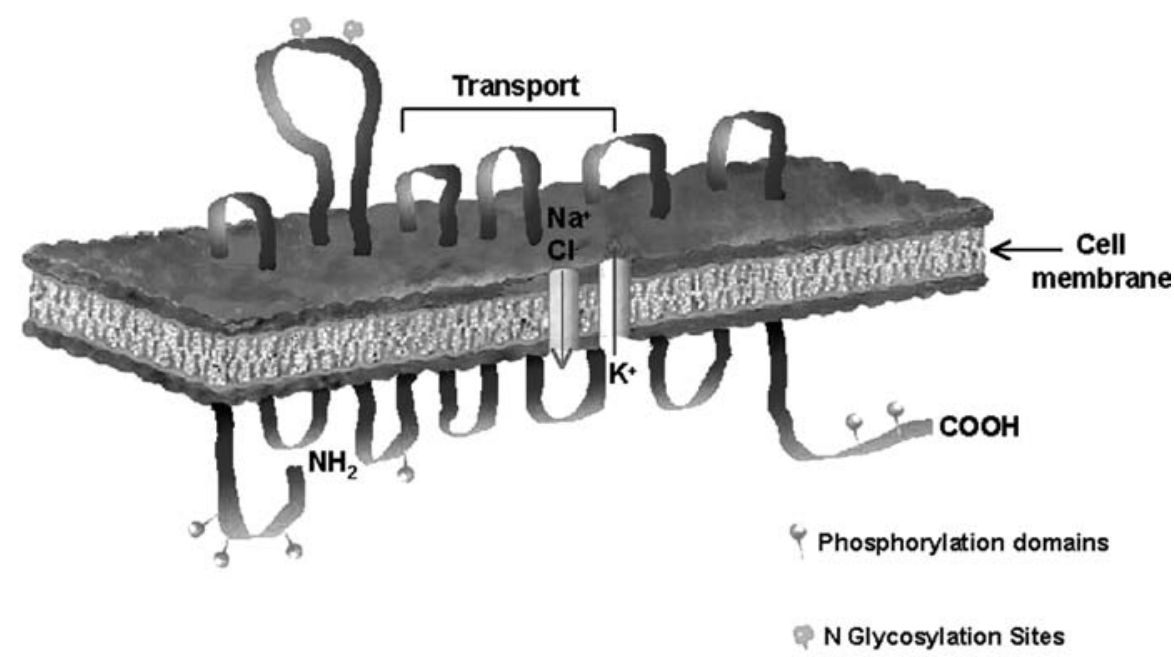

Intracellular

Fig. 1 The role of glia (astrocytes) in accumulating, metabolizing and conserving synaptic GABA and glutamate (Dale Horst 1995). Specific membrane transporters move GABA and glutamate into glia cells where GABA is carboxylated $\left(\mathrm{CO}_{2}\right)$ to form glutamate; glutamate in turn is aminated (NH4) to create glutamine. Glutamine is then transported out of the glia and is available to GABAergic and glutamatergic presynaptic neurons for conversion to their respective transmitters. Thus, glia appear to play an important role in salvaging these two ubiquitous and important transmitters

associated with neurotoxicity and neuronal death. Thus, it is of considerable importance that extraneuronal concentrations of glutamate be controlled and that mechanisms exist to limit the synaptic activity of this transmitter. Glial cells have been shown to possess membrane transporters or uptake sites for glutamate; it has also been demonstrated that glutamate uptake into glial cells is the primary route for clearing synaptic glutamate. Once inside the glial cell, the glutamate is metabolized to glutamine, a neuronally inactive substance. The conversion of glutamate to glutamine occurs primarily in glial cells via the enzyme glutamine synthetase. Thus, glial cells play a critical roll in limiting the synaptic concentrations of glutamate and conserving the neurotransmitter for reuse. An important element in the above function is the maintenance of appropriate levels of glutamine synthetase activity in glial cells. Significant factors in the regulation of glutamine synthetase activity are glucocorticoid stimulation of gene expression and the absolute requirement for the astrocyte and neuron to be in juxtaposition. The critical neuronal factor required for gene expression of glutamine synthetase has not been identified (Vardimon et al. 1999).

Further evidence of the role astrocytes play in limiting synaptic levels of glutamate is seen in the influence that neuronal factors play in the regulation of 
glutamate transporter expression in glial membranes (Swanson et al. 1997; Schlag et al. 1998). A soluble, diffusible substance secreted by neurons has been shown to increase the expression of glutamate transporter molecules in astrocytes. Thus, it would appear that the level of neuronal activity plays a role in regulating the rate at which glutamate is transported into the glia for inactivation as described above. Although the substance has not been identified, the above effects can be mimicked by cyclic adenosine $5^{\prime}$-monophosphate (AMP) analogs (Swanson et al. 1997; Schlag et al. 1998).

Neuron dependent expression of two types of calcium channels has also been shown in astrocytes (Corvalan et al. 1990). The agent responsible for this intercellular communication has not been identified but may be cyclic AMP or a related substance (Corvalan et al. 1990).

Recent investigations have revealed a metabolic coupling between glia and neurons (Poitry-Yamate et al. 1995; Tsacopoulos and Magistretti 1996; Bacci et al. 1999). Considerable energy is consumed by the various processes of synaptic transmission. The preferred energy source for brain function is glucose. Astrocytes are capable of transporting glucose across the cell membrane via an active, carrier-assisted mechanism. Since astrocytes are well know to be in intimate contact with the brain's vascular system, it is assumed that glucose is transported directly into the glia from the circulation. Inside the glia, glycolysis transforms the glucose to lactose and, in the process, provides energy for the transport of transmitters and ions across the glial membrane. Lactose is then transferred out of the glia and accumulated by neurons where it is the preferred substrate for oxidative metabolism. This energy transfer process is stimulated by the uptake of neurotransmitters such as glutamate and gamma aminobutyric acid (GABA). Neurotransmitter uptake by glia is accompanied by the influx of sodium ions. The accumulation of sodium ions stimulates a $\mathrm{Na}^{+} / \mathrm{K}^{+}$adenosine triphosphatase (ATPase) pump that consumes adenosine $5^{\prime}$-triphosphate (ATP) and exchanges intracellular sodium ions for extracellular potassium ions. The activity of the ATPase stimulates the metabolism of glucose resulting in increased lactose production. Thus the production of the metabolic precursor keeps pace with the overall synaptic activity.

In some cases astrocytes have been shown to possess functional ion channels controlled by neurotransmitter receptors. In this way, glia have been associated with long-distance signal transmission in brain via gap junctions across glial membranes (Cornell-Bell et al. 1990; Cornell-Bell and Finkbeiner 1991; Robinson et al. 1993). The observation that glial gap junctions are in part controlled by components of second messenger systems (Enkvist and McCarthy 1992) supports the active role of glia cells in brain function. It has been suggested that glial dysfunction plays a role in epilepsy and in the degenerative diseases Parkinson's and Huntington's (Ransom and Sontheimer 1992). Although several psychopharmacological agents interact with glial elements, as well as those same elements found on neurons, the contributions of these glial interactions to the agents' overall pharmacodynamics remain largely unknown and the subject of intensive investigation. 
One exciting, potential therapeutic lead for the treatment of neurodegenerative disorders is found in research with glial cell line-derived neurotrophic factor (GDNF). GDNF was isolated from a culture of glial cells and found to stimulate the growth of embryonic dopamine neurons (Bohn 1999). Since this observation on dopaminergic neurons was made, GDNF has been found to elicit a trophic response on several other brain neuron types including motor neurons and noradrenergic, cholinergic, and serotonergic neurons (Bohn 1999). Other neurotrophic factors have been identified with activity similar to that of GDNF (Saarma and Sariola 1999); these include neurturin, persephin, and artemin. GDNF is a chain of 134 peptides synthesized from a larger propeptide. It exerts its biological activity through a series of complex receptor interactions, requiring cofactors and a tyrosine kinase receptor (Grondin and Gash 1998; Saarma and Sariola 1999). Although the exact role of GDNF in brain development and maintenance is not known, GDNF has been shown to be active in a variety of animal models for Parkinson's disease (Grondin and Gash 1998; Lapchak 1998; Bohn 1999) and has been proposed as a potential therapeutic agent for the treatment of Parkinson's disease, amyotrophic lateral sclerosis, and other neurodegenerative diseases. While the activity of GDNF is promising, in that it demonstrates efficacy in a variety of midbrain, dopamine-deficient models, many hurdles must be crossed before it can become a therapeutic reality. For example, what are the effects of long-term GDNF administration (dopamine enhancement may result in psychotic symptoms)? How will the substance be administered (it is a long chain peptide and will not cross the blood-brain barrier)? Are there subpopulations of patients who will not respond to GDNF (they may be deficient in receptors or essential components of the messenger system)? A small sampling of patients with Parkinson's disease did not reveal genetic abnormality in the GDNF gene (Wartiovaara et al. 1998).

\section{2}

\section{Neurons}

The basic function of neurons is to convey electrical signals in a highly organized and integrated way, each neuron receiving input from many other neurons and, in turn, providing input to many other neurons. This function is the product of complex chemical processes transmitting signals across neuronal synapses-a symphony of intra- and interneuronal events, layers of feedback, and control mechanisms assuring the correct or appropriate response. Although chemical transmission is a complex, multi-stepped system, it provides for maximum flexibility and unidirectional flow of neuronal signals.

\section{3}

\section{The Electrical Nature of Neurons}

Resting neurons maintain an electrical polarization between the inside and outside of the cellular membrane. This polarization is negative on the inside and 
positive on the outside of the neuron. Key elements in maintaining the polarized state include the presence of large (nondiffusible), intracellular, negatively charged, proteins and specific ion pumps, located in neuronal membranes that use cellular energy to pump ions against concentration gradients. Changes in the state of transmembranal polarization are affected by a system of specific ion channels activated by neurotransmitter substances or by the degree of transmembrane polarization (voltage sensitive). Ions move through the channels because of concentration (from high to low concentrations) or electrogenic (opposite charges attract) gradients. Activation of neurotransmitter controlled ion channels reduces the level of polarization to a critical level at which voltage-sensitive channels open and permit the rapid influx of cations (e.g., $\mathrm{Na}^{+}$). This influx completely depolarizes the neuron and even reverses the polarization for a brief period. Membrane ion channels adjacent to the area of depolarization open, thus extending the depolarization along the neuron and causing the formation of an action potential. In this way, electrical signals are carried from one end of the neuron to the other. Repolarization occurs by the opening of voltagesensitive $\mathrm{K}^{+}$channels. Since $\mathrm{K}^{+}$concentrations are high inside the neuron and low outside, $\mathrm{K}^{+}$carries positive charges to the outside of the membrane, making the inside more negative. The restoration of conditions in the resting state is completed by the exchange of intracellular $\mathrm{Na}^{+}$ions for extracellular $\mathrm{K}^{+}$ions. Ion exchange is accomplished by an energy-dependent pump (excellent reviews of the electrical nature of neurons may be found in Levitan and Kaczmarek 1997 and Shepherd 1994).

\section{4}

\section{The Synapse}

The synapse is defined as the juncture of two neurons: the neuron from which the signal is coming is known as the presynaptic neuron, while the receiving neuron is called the postsynaptic neuron. Signals are passed across the synapse by either of two mechanisms. The first is by direct connection of the pre- and postsynaptic neurons via gap junctions (similar to the connection of astrocytes described above). The physiological significance of this type of connection is that transmission is rapid, can occur in two directions, and can synchronize the activity of many neurons. Electrogenic coupling of neurons occurs in only a few populations of neurons located primarily in the brain stem (Baker and Llinas 1971; Korn et al. 1973; Llinas et al. 1974). Cortical precursor cells are also known to communicate via gap junctions (LoTurco and Kriegstein 1991), although this function is lost as the cells develop into mature functioning neurons. Other neurons in the suprachiasmatic nucleus are also known to transmit signals via gap junctions, which are at least partially influenced by the neurotransmitter GABA (Shinohara et al. 2000). These gap junctions may be unique in that they are electrogenic in nature but are influenced by a neurotransmitter substance; they may thus exhibit the advantages of both modes of interneuronal communication. 


\title{
2.5
}

\section{Chemical Transmission}

By far the dominant means of neuron-to-neuron communication or transmission occurs by means of specific chemicals or neurotransmitters. Chemical transmission requires the presence of several elements to operate effectively (Table 2). These elements consist of specific proteins in the form of enzymes,

Table 2 Elements required for chemical transmission

\author{
Presynaptic \\ Enzymes for neurotransmitter synthesis \\ Mechanism for neurotransmitter storage \\ Mechanism for appropriate neurotransmitter release \\ Neurotransmitter receptors for feedback modification of neurotransmitter release \\ Synaptic \\ Mechanism for terminating neurotransmitter action \\ Postsynaptic \\ Neurotransmitter receptors to initiate response \\ Coupler proteins \\ Mechanism for response (ion channels/second messenger systems)
}

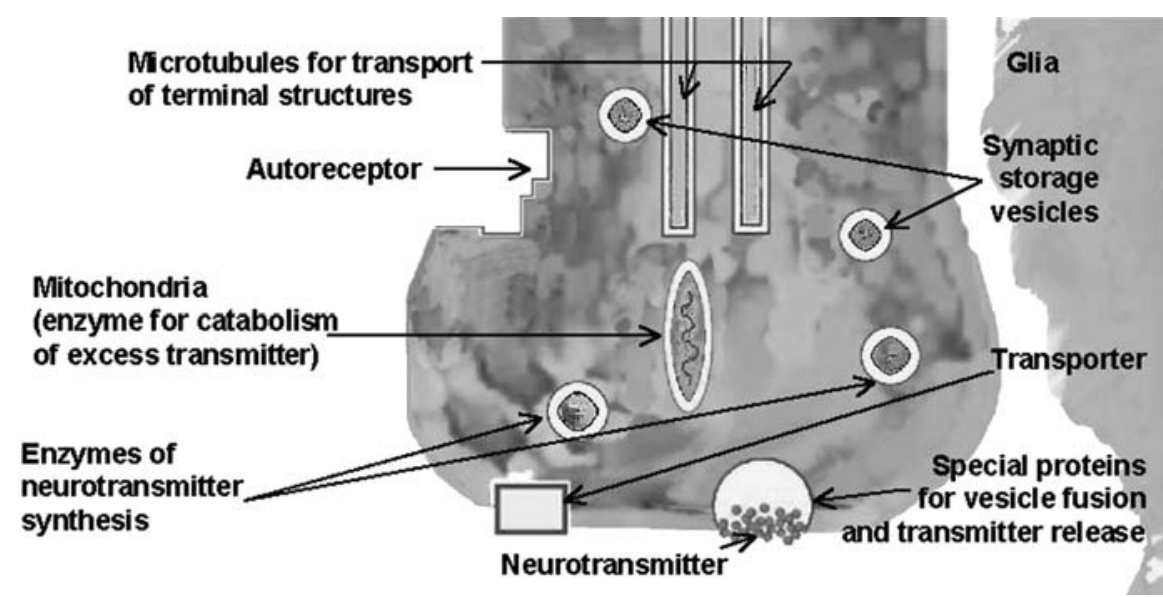

Fig. 2 Typical presynaptic neuron with key structures relevant to neurotransmission (Dale Horst 1995). Microtubules transport storage vesicles, enzymes, and a variety of proteins from the neuronal soma where they are synthesized to the nerve ending where they are required for carrying out their physiological functions. Storage vesicles maintain stores of neurotransmitter molecules for eventual release into the synaptic cleft. Mitochondria contain enzymes vital to providing energy to the neuron and, in many cases, such as the biogenic amines, they contain enzymes such as monoamine oxidase that help regulate neurotransmitter levels in the nerve ending. Calcium and a variety of special fusion proteins fuse the storage vesicle membranes with the neuronal membrane to release the transmitter substance into the synaptic cleft. Reuptake pumps are proteins incorporated into the neuronal membrane that transport the transmitter substance from the synapse into the neuron where it can be reincorporated back into the storage vesicle. Autoreceptors respond to neurotransmitter released from the nerve ending to provide feedback regulation of presynaptic depolarization 


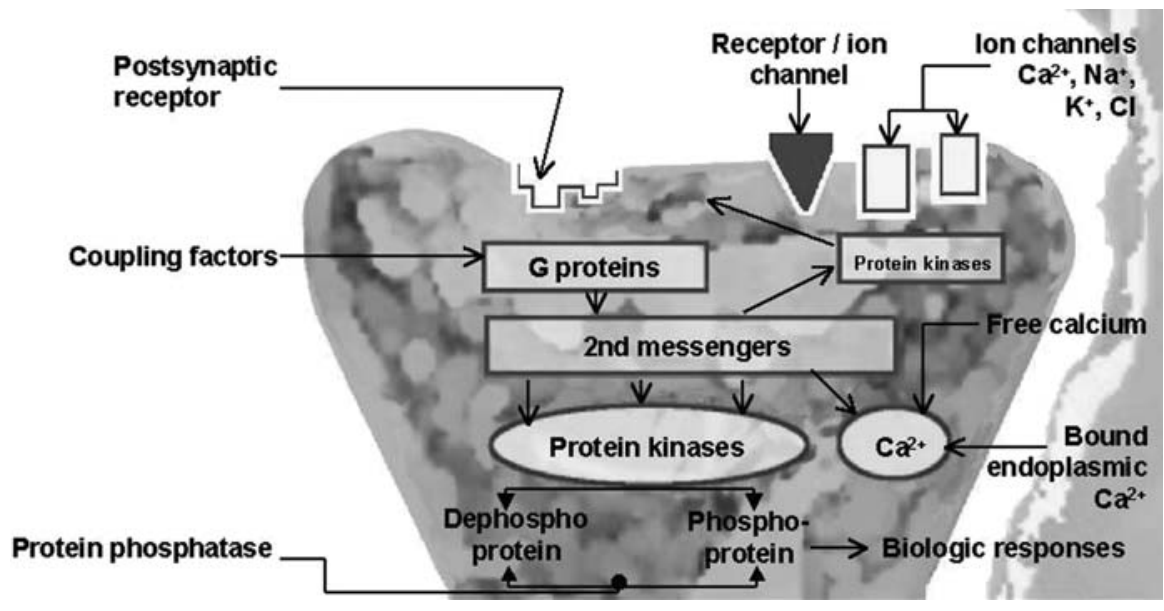

Fig. 3 Typical postsynaptic neuron with key structures relevant to neurotransmission (Dale Horst 1995). Neurotransmitter substances bind to postsynaptic receptors, which may be one of two major types, $G$ protein or ion channel coupled. Other ion channels are regulated by intraneuronal ions such as calcium or potassium as well as transmembrane voltages. $\mathrm{G}$ proteins couple receptors with second messenger systems, which in turn regulate a variety of protein kinases that are responsible for initiating biological responses. Second messengers also directly regulate intraneuronal calcium levels. The various elements in the illustration are shown in their functional sequence, not in their anatomical domains. Postsynaptic receptors, $\mathrm{G}$ proteins, and second messengers are in fact neuronal membrane-associated elements

storage-binding proteins, uptake/membrane transport structures, receptors, and response systems (ion channels/second messenger systems). Each element represents an opportunity for malfunction (disease state) and/or a point for modulation of transmission through pharmacological intervention. In fact, the manipulation of these elements serves as the basis of modern psychopharmacology. The functional relationship of the elements of neurotransmission is illustrated in Figs. 2 and 3.

\subsection{1}

\section{Neurotransmitter Synthesis}

The final enzymatic steps in synthesizing a neurotransmitter generally occur in or near the storage site. This assures maximum efficiency in the neurotransmitter molecules getting to the storage sites. Neuropeptides are a notable exception to this role since their synthesis involves gene activation followed by DNA transcription and RNA translation to form large polypeptides. The polypeptides are then broken down into the component neuropeptides. All of this occurs within the neuronal soma so that the neuropeptides must be transported along the axon to the nerve terminal for storage. In several cases, neurotransmitter synthesizing enzymes are shared by more than one transmitter system. For example, the transmitters norepinephrine and dopamine share the enzymes tyrosine hydroxylase, and L-dopa decarboxylase, while several peptides share common 
peptidases. Although many drugs are known to inhibit specific neurotransmitter synthesizing enzymes, these drugs have not proven useful as therapeutic agents, either because the neurotransmitters they influence are ubiquitous and important to many life processes or because the enzymes influence multiple transmitters and thus produce broad, nonspecific effects.

\subsection{2 \\ Neurotransmitter Storage and Release}

Many neurotransmitters are stored in organelles known as synaptic vesicles (Thiel 1995). These structures-constructed in the soma and transported along the axons, with their full complement of neurotransmitter-concentrate near the nerve terminal. The vesicular membranes contain many specific protein structures involved in the multiple functions of the storage vesicles (Kelly 1999; Krantz et al. 1999; Rahamimoff et al. 1999). Vesicular functions include neurotransmitter synthesis, neurotransmitter transport across the vesicular membrane, neurotransmitter binding inside the vesicle, docking proteins for attaching to the neuronal plasma membrane, calcium binding proteins for membrane fusion and neurotransmitter release, and special coating proteins for vesicular endocytosis and recycling processes.

Calcium ions are an essential element for the release of neurotransmitters. A major mechanism for calcium entry results from the activation of voltage-gated ion channels located in the plasma membrane (Rahamimoff et al. 1999; Zhang and Ramaswami 1999). Of course, the activation of the voltage-gated ion channels depends on many factors, such as the activity of numerous other membrane ion channels (Rahamimoff et al. 1999) and a variety of presynaptic ligand-gated ion channels (MacDermott et al. 1999) as well as autoreceptors (MacDermott et al. 1999). Given the absolute requirement for $\mathrm{Ca}^{++}$in the neurotransmitter release process, it is not surprising that proteins that comprise the voltage-gated calcium channel are intimately bound to specific proteins associated with storage vesicle docking and fusion processes (Catterall 1999). This would ensure that transmitter release is occurring in a microenvironment containing an appropriate concentration of calcium.

Proteins involved in the storage and release mechanisms of neurotransmitters are well conserved in many different transmitter systems so that drugs that interfere with storage and release tend to have broad nonspecific effects. Reserpine is an example of such a drug. Reserpine destroys the ability of presynaptic storage vesicles to transport and store all biogenic amines such as norepinephrine, dopamine, serotonin, and histamine (Krantz et al. 1999). Since this effect is not reversible, recovery from the effects of reserpine requires the synthesis and transport of new storage vesicles to the nerve terminals, a process that requires several days. For these reasons, reserpine had a short-lived and limited use in psychiatry.

The pharmacology surrounding the control of neurotransmitter release via heterosynaptic, ligand-gated mechanisms presents some clinically significant 
examples. Transmitters for the presynaptic, ligand-gated channels include GABA, glutamate, acetylcholine, serotonin, and ATP (MacDermott et al. 1999).

Presynaptic GABA receptors are of the GABA-A type and thus relevant to the inhibitory actions of the benzodiazepines (Tallman et al. 1999). The presynaptic GABA-A receptors are channels for chloride ions, and their activation hyperpolarizes the presynaptic neuron, resulting in inhibition of presynaptic release of neurotransmitter. Presynaptic cholinergic receptors are of the nicotinic type and, when activated, tend to depolarize the neuron by admitting sodium and calcium ions. The activation of these presynaptic receptors by nicotine is the source of tobacco smoke's central pharmacological and addictive properties (Grady et al. 1992; Wonnacott 1997; Yeomans and Baptista 1997; MacDermott et al. 1999; Watkins et al. 1999). Presynaptic serotonin receptors are of the 5-hydroxytryptamine $3\left(5-\mathrm{HT}_{3}\right)$ type; when activated, they admit calcium into the neuron, thus promoting depolarization and transmitter release (Ronde and Nichols 1998). As with all other serotonergic receptors, the activity of the $5-\mathrm{HT}_{3}$ receptors is enhanced by drugs that block the reuptake of serotonin (MacDermott et al. 1999). In addition, ethanol has been demonstrated to influence several of these presynaptic receptors such as GABA-A, glutamate, nicotinic cholinergic, and 5- $\mathrm{HT}_{3}$ serotonergic types (Lovinger 1997; Narahashi et al. 1999). The relevance of ethanol's influence on these structures to its pharmacological actions is the subject of continued investigations.

\subsection{3}

\section{Neurotransmitter Inactivation}

Once liberated into the synapse, neurotransmitters are available to transmit their signals until they are removed or inactivated in some manner. Thus, transmitter inactivation is an important element in controlling synaptic transmission. Rapid inactivation would attenuate transmission, while slow inactivation would accentuate signal transmission. Three major routes for neurotransmitter inactivation are known. First, transmitters may be removed by washout or turnover of the extraneuronal fluid. This occurs at a relatively slow rate in brain and would appear to be inadequate in most situations.

A second mode of transmitter inactivation is by enzymatic degradation of the neurotransmitter. A notable example of this mode is the function of acetylcholine, a major excitatory transmitter in brain, in which the time span in the synapse is vital for proper function. Acetylcholine is rapidly metabolized in the synapse by acetylcholinesterase, a process that splits the transmitter into two parts, acetate and choline. These two components are then transported back into the presynaptic neuron where another enzyme, choline acetyltransferase, rejoins them to form acetylcholine. Thus, these two enzymes and the transport of the precursors across the membrane form an effective and efficient means of rapidly terminating the synaptic activity of the transmitter, while protecting the availability of the precursors required for transmitter synthesis. 
A third mechanism for transmitter inactivation is a variation of the second. In this case, rather than transporting the individual components of the neurotransmitter, the intact transmitter is transported across the presynaptic neuronal membrane and into the cytoplasm, where it is eventually accumulated by storage vesicles and becomes available for release once again. Transport or "reuptake" is accomplished by special transmembrane proteins, which serve as carriers. Since the concentrations of transmitter are generally greater in the presynaptic terminal than in the synaptic fluid, cellular energy in the form of ATP is expended in the reuptake process. Many major transmitters are primarily inactivated by this reuptake process, including the biogenic amines, norepinephrine, dopamine, and serotonin, and the amino acids, GABA, glycine, and glutamine. The transporter proteins for the majority of transmitters have similar properties (Kanner et al. 1994; Nelson 1998; Krantz et al. 1999), such as a requirement for sodium and chloride ions. The transporters characteristically have 12 transmembrane sections, with a large extracellular loop between the third and fourth sections. This third loop contains a site or sites for glycosylation (Blakely et al. 1997; Gegelashvili and Schousboe 1997; Nelson 1998; Krantz et al. 1999). Inhibition of glycosylation at these sites appears to diminish the function or efficiency of the transporter but does not influence substrate affinity (Melikian et al. 1996).

A second set of transporters, similar to, but genetically distinct from, those found in the neuronal membrane, is located within the membranes of the neurotransmitter storage vesicles. These transporters move the neurotransmitters from the neuronal cytoplasm to the interior of the vesicles, where they are ready for release once again (Krantz et al. 1999).

The serotonin transporter has been the subject of intensive investigation because it is the site of action for the selective serotonin reuptake inhibitors (SSRIs), the drugs of choice in the treatment of major depression. A transporter protein structure approximating the serotonin transporter is shown in Fig. 4. In common with other neurotransmitter transporters, the serotonergic transporter has 12 transmembrane sections with both the amino and carboxyl terminals within the neuron (Blakely et al. 1997; Nelson 1998). The serotonin transporter molecule includes intraneuronal sites for phosphorylation that are critical for the regulation of transporter activity (Blakely et al. 1997, 1998). These sites appear to be primarily phosphorylated by kinase $C$ and dephosphorylated via the action of phosphatase 2A (Blakely et al. 1998). Phosphorylation inactivates the transporter molecules and therefore slows the clearing of serotonin from the synaptic cleft. This phosphorylation process likely serves as a kind of feedback control, since kinase $\mathrm{C}$ activity is regulated via neurotransmitter interaction with neuroreceptors (see the section "Second Messengers" later in this chapter and Fig. 7).

Recognition or binding sites for serotonin to the transporter are located at extraneuronal loops of the molecule. A precondition for substrate binding is the binding of one each of sodium and chloride ions to the transporter (Nelson 1998; Krantz et al. 1999). Presumably the binding of these ions places the tertia- 


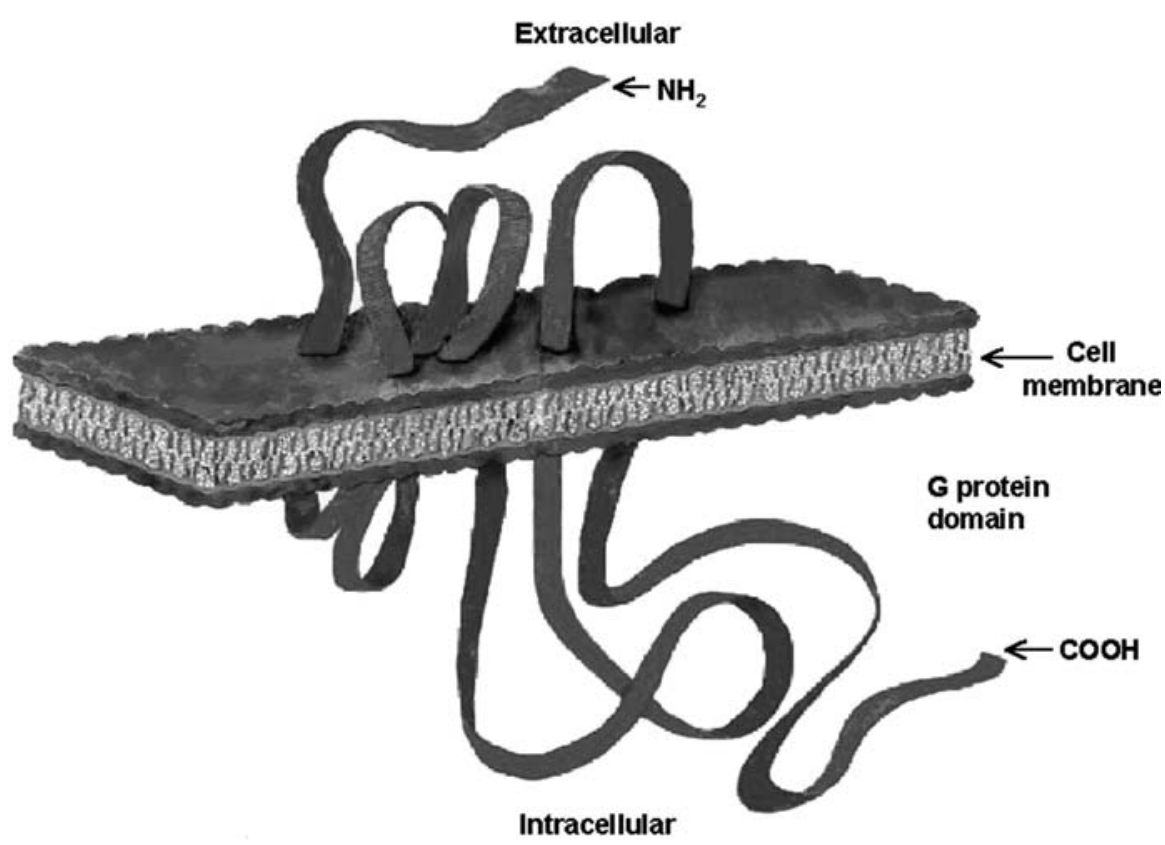

Fig. 4 A typical neurotransmitter protein (Dale Horst 2000). Neurotransmitter transporters, while exhibiting specificity for the neurotransmitter being transported, have many structural features in common. Each has 12 transmembrane sections, a large extraneuronal loop between the third and fourth transmembrane sections, intraneuronal sites for phosphorylation $(\mathrm{P})$, and a requirement for ion binding. The figure approximates a serotonin transporter

ry configuration of the transporter in the best position for substrate binding. The exact location of the site of attachment of inhibitory drugs, such as many of the antidepressant compounds, is not known for all drugs, but it most likely occurs at a variety of external sites. The tricyclic antidepressants are known to bind to the central loops (Blakely et al. 1991; Nelson 1998) in the transport domain for serotonin.

The transporters for several types of neurotransmitters, including those for the amino acids, GABA and glutamate, the catecholamines, dopamine and norepinephrine, and the biogenic amine, serotonin, have long been known to require the presence of sodium and chloride ions in order to function. In general, binding of these monovalent ions appears to be required in order for the neurotransmitter to bind to the transporter. Recent information suggests that transporters for the neurotransmitters may actually serve a significant role as ion channels and thus play a part in neuronal function and regulation of neuronal activity (Lester et al. 1996; Galli et al. 1997; Nelson 1998; Krantz et al. 1999). Although the ion requirements may vary depending on which transporter is involved, the basic mechanisms appear to be similar for the entire family of transporters. 
As an example, the serotonin transporter appears to function with neutral stoichiometry. Thus, $\mathrm{Na}^{+}, \mathrm{Cl}^{-}$, and serotonin ${ }^{+}$are transported into the neuron, while $\mathrm{K}^{+}$is transported out, resulting in no net transfer of charge (Galli et al. 1997; Krantz et al. 1999); yet it has been demonstrated that significant charge transfer does occur through the serotonin transported (Galli et al. 1997). The exact nature of this transfer is not known, but clearly the transporter is acting as an ion channel.

These findings raise interesting questions about the primary function of transporters. It has always been assumed that the primary role of transporters is to remove neurotransmitter from the synapse and to do so in a way that conserves neurotransmitter for reuse. This recently reported information raises the possibility that the transporters' primary role is as an ion channel, with the transport of neurotransmitters serving as a channel-regulating mechanism in addition to providing for the conservation of neurotransmitter (Lester et al. 1996; Galli et al. 1997; Krantz et al. 1999).

This novel perspective of the neurotransporters may provide a solution to an old puzzle concerning the mechanism of action of antidepressants. It is well known that a few weeks of treatment with antidepressants is needed before the onset of clinical response, and yet blockade of neurotransmitter reuptake is immediate. Since reuptake blockers appear to block the ion channel activity of the transporters as well as their transport function (Lester et al. 1996; Galli et al. 1997), it may be that the significant pharmacological action of the reuptake inhibitor antidepressants is related more to the presynaptic, intraneuronal, ionic milieu than to increased synaptic neurotransmitter concentrations.

Whether transporter or ion channel, these structures are important for proper brain function. It has been found that approximately $4 \%$ of the human population have a genetic defect that reduces the transcription process for the serotonin gene, resulting in individuals with reduced transporter function (Lesch et al. 1996). Such individuals have been found to demonstrate relatively high anxiety-related traits (Lesch et al. 1996). In addition, it has been suggested that this defect has a possible link to neurodevelopment and neurodegenerative disorders (Lesch and Mossner 1998).

In the case of the biogenic amines, while reuptake is the major means of limiting their synaptic activity, significant contributions to inactivation are made via the enzymes catechol-O-methyl transferase (Guldberg and Mardsen 1975; Mannisto et al. 1992) and monoamine oxidase (Singer and Ramsay 1995). Inactivation by these enzymes does not result in any known reusable or physiologically active products. The reuptake sites for the biogenic amines exhibit some specificity for each amine, but the sites for each amine appear to be identical on all neurons and in all brain regions containing that amine. Thus, it is possible to design a drug that will specifically block the reuptake of a single bioamine, and will influence reuptake to the same extent at all neurons containing that amine. As will be discussed later, this specificity is an important factor in therapeutic drug design. 
Unlike the biogenic amines, the amino acid transmitters are taken up by both presynaptic neurons and by adjacent glial cells (Jursky et al. 1994; Kanai et al. 1994; Kanner et al. 1994) (Fig. 1). Within the glia, GABA and glutamate are metabolized to glutamine, which is then transported out of the glia and into GABA and glutamate presynaptic neurons where it is converted back to either GABA or glutamate (Shank et al. 1989). The physiological significance of this dual uptake system is not fully understood. Also, unlike the biogenic amines, amino acid transporters occur in multiple variations for each of the transmitters. Thus, three variations of the glutamate transporter (Kanai et al. 1994) have been identified, while four are known for GABA and three for glycine (Jursky et al. 1994). As more is learned about the physiological role of these various transporter subtypes, they may prove to be useful sites for specific modification by drugs.

The pharmacological manipulation of reuptake or transport sites has been an area of intensive activity in developing drugs for the treatment of major depression. The discovery that tricyclic antidepressants, such as imipramine and amitriptyline, had the ability to be potent reuptake blockers of norepinephrine and serotonin led to the early hypothesis that depression was the result of an insufficiency of these biogenic amines and that this insufficiency was corrected by reducing the rate at which these transmitters were removed from the synapse. This hypothesis was supported by other pharmacological and biological observations. Recent clinical success with a new class of antidepressants, the SSRIs, underscores the importance of amine reuptake as an appropriate mechanism of action for antidepressant activity, although it is now apparent that reuptake inhibition alone may not be directly responsible for the antidepressant activity. Rather, reuptake inhibition initiates changes or adjustments in receptors, ion fluxes, and intracellular messenger systems that alter neurotransmission in key pathways (Kilts 1994; Paul et al. 1994; Galli et al. 1997).

\subsection{4}

\section{Receptors}

Neuroreceptors are specific, membrane-bound proteins that bind neurotransmitter molecules and translate that molecular attachment into a physiological response. The amino acid sequence of each receptor type imparts a specificity for the particular neurotransmitter that will bind to it. Of particular importance in defining a receptor is that a physiological response results when the receptor is activated. Many proteins are capable of binding neurotransmitter substances but are not capable of eliciting a response. Such binding proteins are better referred to as acceptors.

Neuroreceptors may be placed into four broad categories, depending on the mode of action of their physiological response (Cooper et al. 1996). The most prevalent of these are those receptors that connect to a second messenger system through one of a family of proteins referred to as G proteins. This receptor type is characterized by having seven transmembrane sections of the protein 


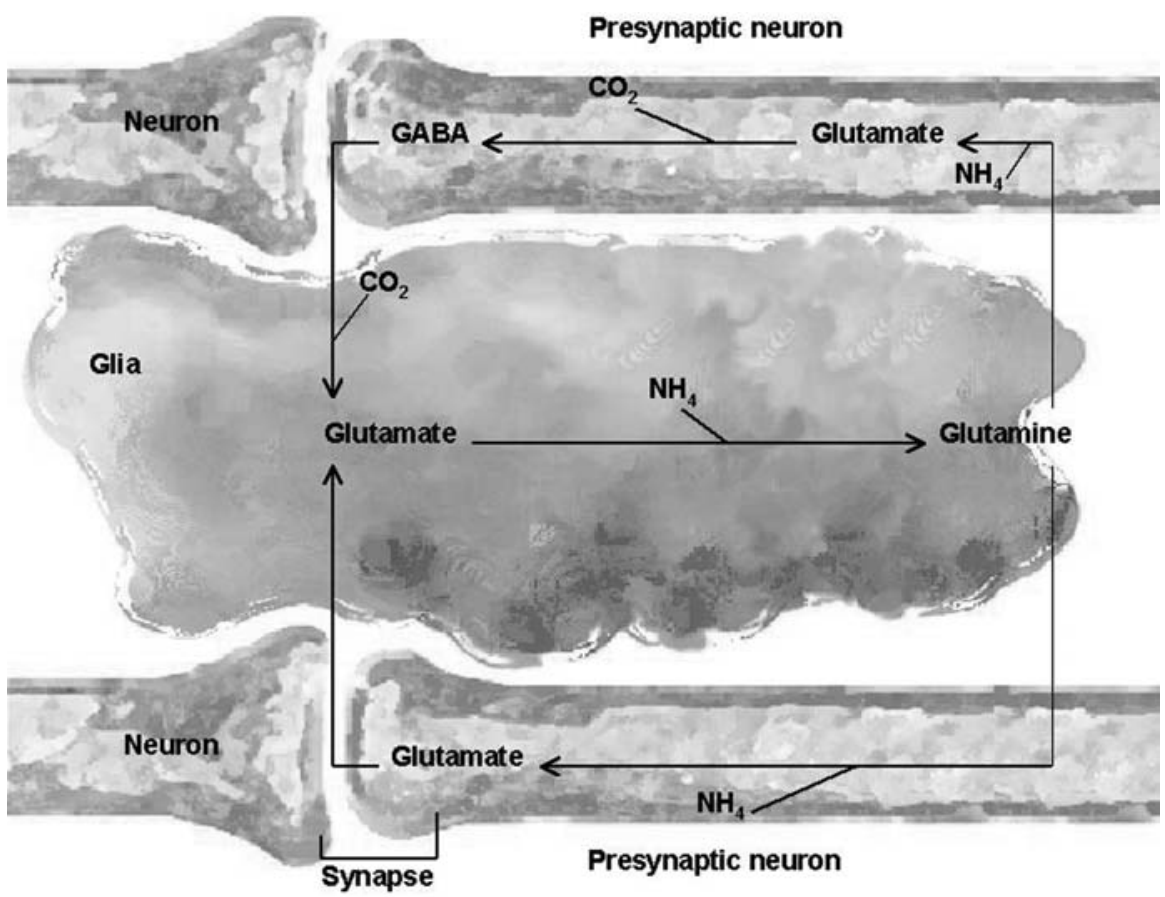

Fig. 5 A typical G protein-coupled neurotransmitter receptor (Dale Horst 1995). Receptors of this type have seven transmembrane sections with the carboxyl terminal on the inside of the neuron. The figure approximates a serotonin $1 \mathrm{~A}$ receptor. Receptors of this type vary with regard to their amino acid composition and the lengths of the extra- and intracellular segments

with extracellular and intracellular loops that serve as neurotransmitter binding sites and sites for receptor regulation (Fig. 5).

A second class of receptors consists of those that form membrane ion channels or ionophores. Stimulation of receptors in this class opens ion channels specific for sodium, potassium, calcium, and chloride ions. The receptor/ion channel consists of five individual proteins, each with four transmembrane sections. The receptors are made up of a combination of protein subtypes; each subtype may exist in several variations. Thus, receptor/ion channels for a specific neurotransmitter may exist in several variations.

The third receptor class consists of receptors that attach to allosteric sites on other neuroreceptors that regulate receptor ligand affinities. Examples of receptors that act at allosteric sites include the benzodiazepine and associated receptors, which modify GABA receptor activity, and the glycine B receptor, which is associated with the $N$-methyl-D-aspartate (NMDA) subtype of glutamate receptor. The presence of glycine on the glycine $\mathrm{B}$ receptor is one of the requirements for glutamate activation of the NMDA receptor.

The fourth receptor class is made up of intraneuronal receptors best characterized by steroid transcription factor binding and the synthesis of various com- 
ponents of synaptic transmission, such as enzymes, receptors, and second messengers systems (Joels and de Kloet 1994). As might be expected, the effects mediated by these receptors have a slow onset and persist over an extended period of time.

Neuroreceptors generally exhibit specificity for neurotransmitters and are usually identified by the transmitter that binds to them and to which they elicit a response. The existence of subtypes of receptors for specific transmitters has been known for many decades. For example, acetylcholine receptors were traditionally thought of as being either nicotinic or muscarinic, based on their pharmacological response. It is now known that they not only exhibit different pharmacological characteristics but that they are entirely different in their functions and mode of responses. The nicotinic acetylcholine receptor is a five-protein, sodium ion channel that is opened in the presence of acetylcholine, while the muscarinic receptor is a single-protein unit coupled to a second messenger system (inositol phosphate) by a $\mathrm{G}$ protein.

Historically, receptor subtypes have been identified by pharmacological studies in which specific drugs are used to stimulate or block receptor activity. Such techniques are limited in that they do not differentiate among receptor subtypes as either two different proteins or one protein in different membrane configurations. Pharmacological techniques are also limited in the number of subtypes that can be identified, particularly as the pharmacological differences become increasingly subtle and if very specific pharmacological agents are not available.

In recent years, molecular biological techniques have been used to identify and characterize many new receptor subtypes. Specific genes have been identified that express neuroreceptors subtypes for many of the neurotransmitters. Through these techniques, populations of "pure" receptor types have been produced, which may then be used to identify specific ligands for the receptors. Specific ligands, in turn, are useful for determining the location and density of specific receptors. Methods also exist by which transcription paths are altered to prevent the expression of specific receptors (Lucas and Hen 1995), thus providing animal models that lack specific receptors. Such studies provide important clues to the physiological function of specific receptors (Thomas and Capecchi 1990; Wahlestedt et al. 1993; Furth et al. 1994; Lai et al. 1994; Saudou et al. 1994; Silvia et al. 1994; Standifer et al. 1994; Zhou et al. 1994; Tecott et al. 1995).

As shown in Table 3, receptors for various transmitters come in a variety of subtypes. For example, 14 subtypes have been identified for serotonin, with the possibility of more to be discovered (Lucas and Hen 1995). Nearly all receptors for the various neurotransmitters come in several subtypes. This fact is very important from a pharmacological perspective, since it means that there is the possibility of identifying compounds for a specific receptor subtype, thus limiting the pharmacological effects.

Neuroreceptors are important sites for pharmacological intervention in psychiatric disorders. For example, all antipsychotic medications are known to have antagonist activity at dopamine receptors. Antidepressant drugs are well known 


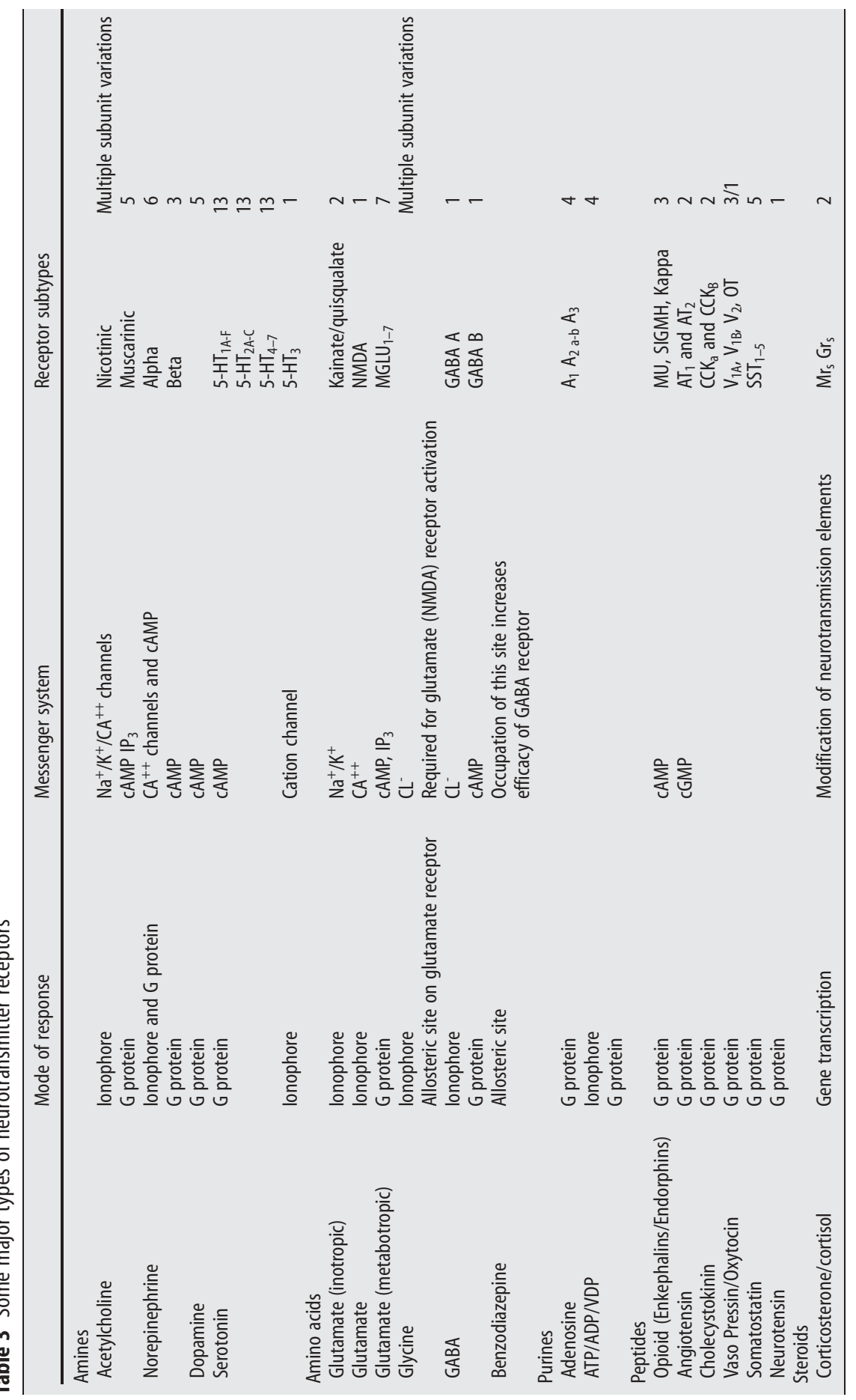


to influence receptors either directly as antagonists or indirectly by up or down regulation of receptor populations (Kilts 1994). Many antidepressants, the tricyclic antidepressants in particular, are known to interact with receptors of several neurotransmitter systems. Anxiolytic agents, the benzodiazepines and buspirone, exert their pharmacological actions through interaction with benzodiazepine and serotonin $\left(5-\mathrm{HT}_{1 \mathrm{~A}}\right)$ receptors, respectively.

Drugs may interact with receptors in one of several ways. They may bind to the receptor and cause a physiological response similar to that of a natural neurotransmitter; such a drug would be referred to as an agonist. Other drugs may also bind to the receptor but do not elicit a physiological response; rather they prevent agonists from binding to the receptor. Such drugs are described as antagonists. A third type of ligand-receptor interaction is referred to as inverse agonism. An inverse agonist is a drug that binds to a receptor but produces an effect opposite to that of agonist activity. This type of action has been described in studies of the benzodiazepine receptor (Stephens et al. 1986), where a single receptor mediates agonist, antagonist, and inverse agonist activities. Pharmaceutical agents are also known that appear to exhibit mixtures of these basic reactions (e.g., mixed antagonist/agonists that produce partial or limited agonist activities, but may behave as antagonists when in the presence of full agonists).

Another distinctive interaction between psychotropic drugs and receptors is well known to occur with chronic antidepressant treatment. Multiple, but not single, doses of many antidepressant compounds are known to down-regulate beta adrenergic receptors (Wolfe et al. 1978) and NMDA receptors in brain tissue (Paul et al. 1994) (i.e., they reduce the actual number of receptor sites). Since many of these drugs do not interact with these receptor populations directly, the induced changes may be the result of some activity in the second messenger system, although the precise mechanisms for these effects are not known. Since the slow onset of the receptor adaptations is similar to the timing of the onset of the clinical antidepressant effect (Oswald et al. 1972), it has been suggested that one or the other of these changes may be related to the antidepressant effect itself (Caldecott-Hazard et al. 1991; Paul et al. 1994).

\subsection{5}

\section{G proteins}

Serving as linking proteins between extracellular receptors and intracellular effector mechanisms (second messengers), the G proteins [regulatory guanosine 5 -triphosphate (GTP)-binding proteins] constitute a large family of related structures vital to the transmission of interneuronal signals. $G$ proteins are actually heterotrimeric structures composed of one each of three protein subunits termed alpha, beta, and gamma (Rens-Domiao and Hamm 1995). To date, 18 specific alpha subunits, five beta subunits, and seven gamma subunits have been identified. The various subunits are not all interchangeable and some combinations of the subunits are not compatible. 


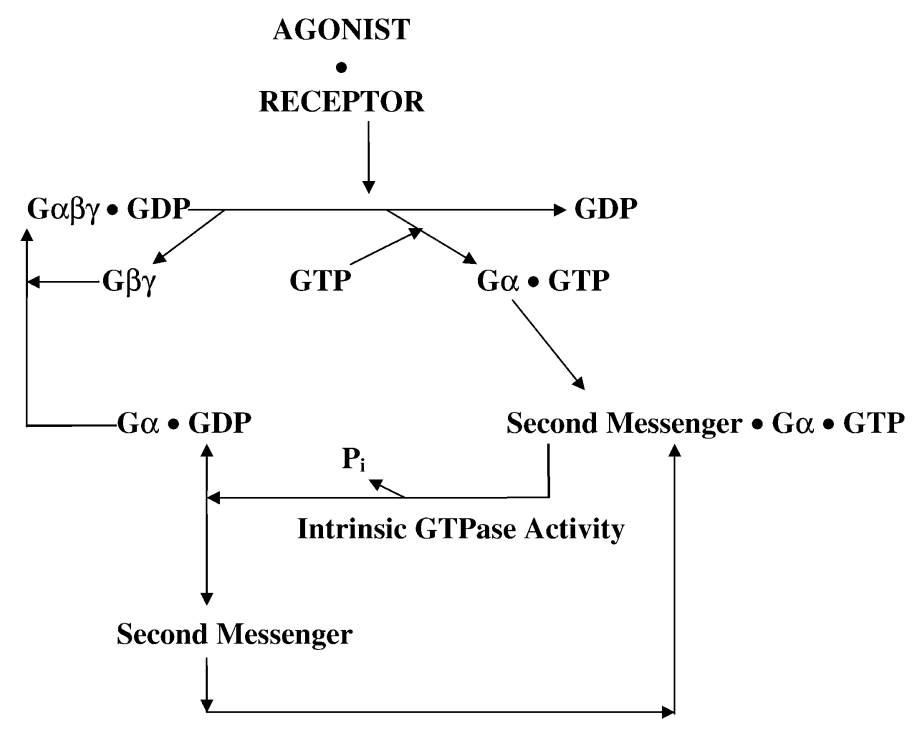

Fig. 6 Regulatory cycle of $G$ protein signal coupling. $G$ protein exists as a tri-protein with alpha, beta, and gamma subunits. Binding of an agonist to a receptor induces the release of the alpha subunit from the beta/gamma subunits and GDP from the alpha subunit. GTP binds to the alpha subunit; this complex then binds to a second messenger (adenylate cyclase or phospholipase C). The intrinsic GTPase converts GTP to GDP, which results in the uncoupling of the alpha subunit from the second messenger. The second messenger is then available for recoupling to an alpha/GTP complex. The alpha/GDP complex then binds to a beta/gamma subunit complex and the cycle is ready to begin again

The alpha subunits play a key role in the transduction process. The alpha unit binds the guanine nucleotide and exhibits intrinsic GTPase activity. It is also the alpha subunit that interacts with the neuroreceptor to initiate the transduction process. Frequently it is the alpha subunit that interacts with the effector proteins, although this function has been attributed to the beta/gamma subunit in some instances (Haga and Haga 1992; Pitcher et al. 1992; Clapham and Neer 1993). Although the alpha subunit disengages from the other two subunits at certain stages of transduction, the beta and gamma subunits remain bound to each other at all times.

The sequence of events for the $G$ protein transduction cycle is illustrated in Fig. 6. The binding of an agonist to a neuroreceptor causes the release of guanosine $5^{\prime}$-diphosphate (GDP) from the alpha subunit with the subsequent binding of GTP. The binding of GTP releases the alpha subunit from the beta/gamma subunit complex and at the same time binds the alpha subunit to the effector protein. Following the interaction with the effector, the alpha subunit converts GTP to GDP (intrinsically) and recombines with the beta/gamma subunits to begin the cycle over again.

All of the neuroreceptors known at this time to stimulate G protein regulatory units are of the seven-transmembrane, helical type. $G$ proteins are known to interact with a variety of effectors, including adenyl cyclase, phosphodiesterase 
(phosphatidylinositol turnover), calcium and potassium channels, and receptorcoupled kinases. Through these effectors, $G$ proteins are involved in both excitatory and inhibitory roles. Through the stimulation of receptor-coupled kinases and the phosphorylation of specific intracellular domains of the receptor proteins, G proteins provide feedback control of receptor sensitivity (Hausdorff et al. 1990).

Relatively little is known about drug influences on $\mathrm{G}$ protein functions. Lithium is known to inhibit $\mathrm{G}$ protein function in the adrenergic stimulation of adenylate cyclase (Belmaker et al. 1990); however, the role of this effect in the therapeutics of lithium is not known. There is insufficient evidence at this time to suggest that $\mathrm{G}$ proteins would provide useful sites for drug interventions. Although the existence of multiple specific subtypes of subunits suggests that drugs with selected and limited activity could be identified, there is no evidence to suggest that specific $G$ proteins are associated with specific neuroreceptors or transmitters. Thus, drugs that alter $\mathrm{G}$ protein function may produce broader effects than desired for therapeutic use. Likewise, no psychiatric disorders have been identified that are the result of defects in $G$ protein regulatory systems. As more is learned about this vital link in neuronal transmission, opportunities for pharmacological manipulation may become more evident.

\subsection{6}

\section{Second Messengers}

As stated earlier, many types of neuroreceptors are connected via a family of $\mathrm{G}$ proteins to one of two classes of second messenger systems, the cyclic adenosine monophosphate (cAMP)/protein phosphorylation system or the inositol triphosphate/diacylglycerol system. Each of these two systems is regulated by the action of $\mathrm{G}$ proteins and the effectors for each system include protein kinases that catalyze the transfer of the terminal phosphate group of ATP to a wide variety of substrate proteins (Table 4). In addition to activating protein kinases, the inositol triphosphate pathway is directly involved in the regulation of intraneuronal calcium concentrations. Unlike the localized effects of changes in ions, second messenger actions are known to spread over long distances in neurons, thus influencing many types of neuronal functions (Kasai and Petersen 1994).

Table 4 Classes of proteins that are targets for phosphorylation by protein kinases

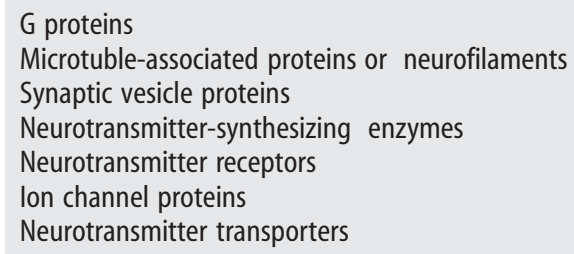


EXTRANEURONAL STIMULATORY RECEPTOR

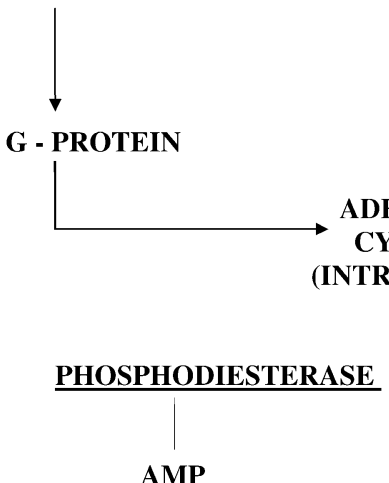

EFFECTOR
EXTRANEURONAL INHIBITORY RECEPTOR

PROTEIN KINASES

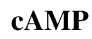

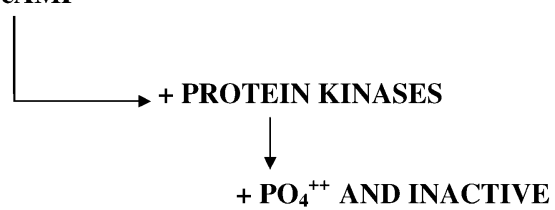

Fig. 7 Regulation and actions of the second messenger adenylate cyclase. Adenylate cyclase is either stimulated or inhibited in its production of cAMP (cyclic adenosine monophosphate) by specific receptors and $\mathrm{G}$ proteins. CAMP stimulates a variety of protein kinases, which in turn phosphorylate $\left(\mathrm{PO}_{4}{ }^{++}\right)$ an effector which activates it and produces biological responses. CAMP is inactivated by the enzyme phosphodiesterase, which converts CAMP to AMP

Neuroreceptors, through specific G proteins, either stimulate or inhibit the enzyme adenylate cyclase that catalyzes the formation of cAMP (Gilman 1989). cAMP in turn binds to protein kinases that activate specific effector proteins through the process of phosphorylation (Fig. 7 and Table 4). A key element in this pathway is the intraneuronal concentration of cAMP. The rate of synthesis of cAMP is the ratio of stimulatory to inhibitory receptor input, while the rate of metabolic degradation of cAMP is determined by the activity of the enzyme, phosphodiesterase. Multiple genetic forms of adenylate cyclase (Cooper et al. 1995), and phosphodiesterase (McKnight 1991) have been identified. More than 300 specific forms of protein kinase are known (Walsh and Van Patten 1994), resulting in diverse activities.

In the case of the inositol/diacylglycerol system, extraneuronal signals are transmitted via a neurotransmitter receptor through a $\mathrm{G}$ protein to a phosphodiesterase, phospholipase $C$, which in turn hydrolyzes phosphatidylinositol-4,5bisphosphate (PIP2), an intermembrane-bound phospholipid (Fig. 8). The products of this hydroxylation are inositol 1,4,5-trisphosphate $\left(\mathrm{IP}_{3}\right)$ and diacylglycerol, both of which serve second messenger roles (Hokin and Dixon 1993). $\mathrm{IP}_{3}$ diffuses to the endoplasmic reticulum and stimulates a specific $\mathrm{IP}_{3}$ receptor 


\section{EXTRANEURONAL}

STIMULATORY RECEPTOR

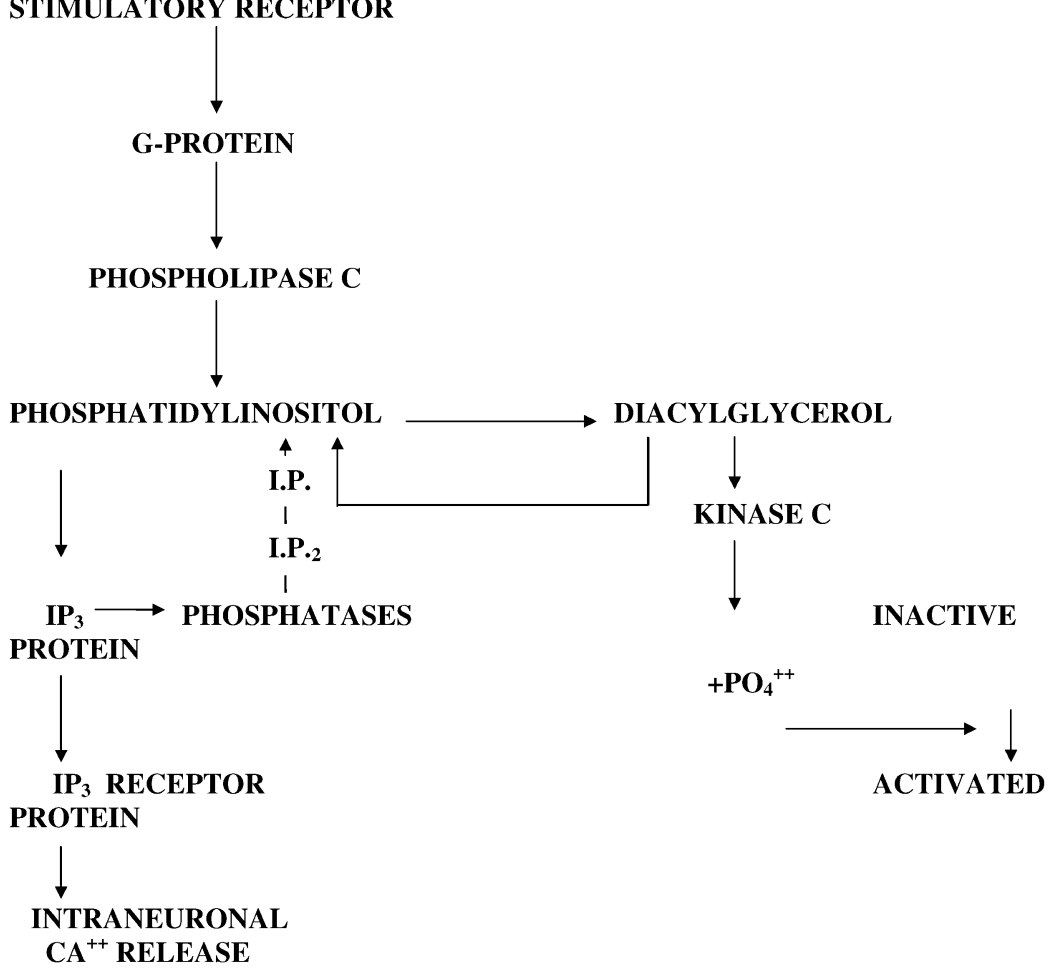

Fig. 8 Intraneuronal actions of phospholipase $C$ activity. Phospholipase $C$ is activated via a receptor stimulated $\mathrm{G}$ protein. Phospholipase $\mathrm{C}$ splits phosphatidylinositol into inositol triphosphate $\left(\mathrm{IP}_{3}\right)$ and diacylglycerol moieties. The diacylglycerol stimulates kinase $C$, which activates effector proteins through phosphorylation. The $\mathbb{I P}_{3}$ binds to a receptor on the endoplasmic reticulum. Stimulation of this receptor releases bound calcium into the cytoplasm. $\mathbb{I P}_{3}$ is inactivated by a series of phosphatases. Inositol is reincorporated into phosphatidylinositol. The anti-manic drug lithium is a potent inhibitor of phosphatase and blocks the reincorporation of inositol back into phosphatidylinositol

to release sequestered $\mathrm{Ca}^{++}$. The $\mathrm{IP}_{3}$ receptor is now known to exist in multiple subtypes (Marshall and Taylor 1993; Danoff and Ross 1994). The activity of $\mathrm{IP}_{3}$ receptors are regulated by several allosteric sites for $\mathrm{Ca}^{++}$, adenine nucleotides, and protean kinases. $\mathrm{IP}_{3}$ is inactivated by the removal of phosphate through a series of phosphatase enzymes and the inositol moiety recycled back to phosphatidylinositol.

The diacylglycerol formed by the action of phospholipase $\mathrm{C}$ activates a widely distributed kinase, kinase $\mathrm{C}$. Kinase $\mathrm{C}$ phosphorylates several proteins associated with a variety of neuronal membranes, such as those of synaptic vesicles, microtubules, receptor proteins (Nalepa 1994; Premont et al. 1995), and transporters (Blakely et al. 1998). The action of diacylglycerol is quite short, and it is 
rapidly recycled into phosphatidylinositol or metabolized to enter prostaglandin synthetic pathways.

The activity level of a protein that is activated by phosphorylation is determined by the relative rates of phosphorylation verses dephosphorylation. Calcineurin has been identified as a major factor in the dephosphorylation of a wide variety of proteins with key roles in synaptic transmission (Yakel 1997). These processes include ion channels (receptor and voltage gated), neuroreceptors, and neurotransmitter release. Calcineurin is approximately $50 \%$ bound to the neuronal membrane and thus influences many membrane-bound processes.

Calcineurin is composed of two subunits, designated A and $\mathrm{B}$. The A subunit binds $\mathrm{Ca}^{++}$and calmodulin; $\mathrm{Ca}^{++}$binding is required for the binding of calmodulin. The $\mathrm{B}$ unit also binds $\mathrm{Ca}^{++}$and full phosphatase activity is not realized unless all of these components are in place (Yakel 1997).

Calcineurin has been demonstrated to regulate receptor gated ion channels, such as those gated by glutamate (NMDA), GABA, serotonin $\left(5-\mathrm{HT}_{3}\right)$, and acetylcholine (nicotinic). It appears to have a major influence on voltage gated $\mathrm{Ca}^{++}$channels. Calcineurin is also implicated in the processes of synaptic release of neurotransmitters and the recycling of the synaptic structures themselves. Nitric oxide synthetase is a substrate for calcineurin, the dephosphorylation of nitric oxide synthetase increasing its activity and enhancing the production of nitric oxide. This latter process may be involved in certain neurotoxicity mechanisms. Finally, calcineurin regulates gene transcription and synaptic plasticity in learning and memory-related processes (Table 5).

Although no psychotherapeutic agents are known to exert effects by influencing calcineurin, immunosuppressant drugs such as cyclosporin A and FK506 are known to be potent inhibitors of calcineurin (Yakel 1997). The clinical significance of these immunosuppressant drugs with respect to their inhibition of calcineurin is not known; however, these drugs are known to cause neurotoxici-

Table 5 Synaptic structures that are substrates for calcineurin regulation (from Yakel 1997)

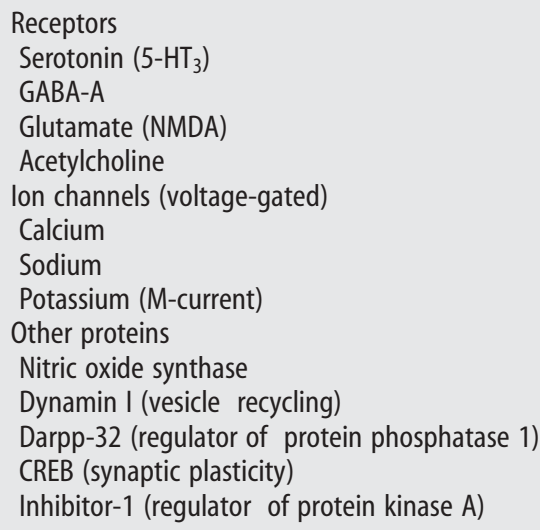


ty and sympathetic hypertension in in vivo animal studies (Hughes 1990; Lyson et al. 1993; Yakel 1997).

Traditionally, the components of second messenger systems have not been the primary targets of psychopharmacological agents. This is because second messengers are few in number and, therefore, are not specific or selective compared to neurotransmitter receptors or reuptake sites. For example, a drug that influences the intracellular levels of cAMP would be expected to have the same influence in many types of synapses simultaneously or, for that matter, in many kinds of tissues, since second messengers exist in many types of cells outside the nervous system (Nishizuka 1995). Of course, now that subtypes of such elements as phospholipase, phosphodiesterase, adenylate cyclase, and $\mathrm{IP}_{3}$ receptors are known, the identification of more selective agents may be possible.

At this time, only one psychotherapeutic agent is known that is likely to have a mechanism of action that involves a second messenger system. Lithium, as an agent for treating mania, is well known to block inositol monophosphatase, a critical enzyme in the synthesis of phosphatidylinositol and the subsequent production of $\mathrm{IP}_{3}$ (Hokin and Dixon 1993; Parthasarathy et al. 1994). It has been suggested that this is the mechanism of lithium's anti-manic action, since the influences on $\mathrm{IP}_{3}$ occur at therapeutic doses (Baraban et al. 1989; Belmaker et al. 1990). Other pharmacological observations support this hypothesis (Kofman and Belmaker 1993). It is becoming more evident that there is a great deal of interaction among the various components of the second messenger systems and that some drug effects may be accounted for in this way. For example, the antidepressants are known to influence cAMP levels through their influences on adrenergic receptors; however, they also influence the inositol/diacylglycerol system by modifying the action of kinase C (Nalepa 1994). Thus, antidepressant effects may be produced through more than one neurotransmitter system.

The ultimate influence that an agonist exerts upon a neuronal systems depends on a complex series of interactions between the agonist and the receptor, the receptor and the $G$ protein, and the $G$ protein and the second messenger system (Kenakin 1995a, 1995b). Although it has not yet been demonstrated, different agonists may influence receptors in ways that alter the interaction of the receptors with a variety of $G$ proteins. It is known that receptors may activate more than one kind of $\mathrm{G}$ protein, thus providing qualitatively differing biological responses. It has also been demonstrated that the relative concentrations of receptors to $G$ proteins may be an important determinant in the qualitative response to agonist activity. High concentrations of receptors relative to G proteins cause an interaction with multiple $G$ proteins with multiple effects. The roles that these factors play in disease states or in the mechanisms of action of drugs are not known at this time; however, psychotropic agents such as antidepressants and antipsychotics are certainly well known for their influence on receptor populations, and some of their pharmacological actions may result from changes in the interaction of these crucial elements in neurotransmission. 
Acknowledgements. The author gratefully acknowledges permission from the American Psychiatric Press, Inc, Washington, D.C., to reprint the figures, tables, and much of the text of this chapter from The American Psychiatric Press Textbook of Neuropsychiatry, fourth edition (Yudosky and Hales 2002).

\section{References}

Aschner M, Allen JW, Kimelberg HK, LoPachin RM, Streit WJ (1999) Glial cells in neurotoxicity development. Annu Rev Pharmacol Toxicol 39:151-173

Attwell D (1994) Neurobiology: glia and neurons in dialogue. Nature 369:707-708

Bacci A, Verderio C, Pravettoni E, Matteoli M (1999) The role of glial cells in synaptic function. Philos Trans R Soc Lond B Biol Sci 354:403-409

Baker R, Llinas R (1971) Electronic coupling between neurons in the rat mesencephalic nucleus. J Physiol 212:45-63

Baraban JM, Worley PF, Snyder SH (1989) Second messenger systems and psychoactive drug action: focus on the phosphoinositide system and lithium. Am J Psychiatry 146:1251-1259

Belmaker RH, Livine A, Agam G, Moscovich DG, Grisaru N, Schreiber G, Avissar S, Danon A, Kofman O (1990) Role of inositol-1-phosphatase inhibition in the mechanism of action of lithium. Pharmacol Toxicol 66(suppl 3):76-83

Blakely RD, Berson HE, Fremeau RT Jr, Caron MG, Peek MM, Prince HK, Bradley CC (1991) Cloning and expression of a functional serotonin transporter from rat brain. Nature 354:66-70

Blakely RD, Ramamoorthy S, Qian Y, Schroeter S, Bradley CC (1997) Regulation of antidepressant-sensitive serotonin transporters. In: Reith MEA (ed) Neurotransmitter transporters: structure, function, and regulation. Humana Press, Totowa, NJ, pp 2972

Blakely RD, Ramamoorthy S, Schroeter S, Qian Y, Apparsundaram S, Galli A, DeFelice LJ (1998) Regulated phosphorylation and trafficking of antidepressant-sensitive serotonin transporter proteins. Biol.Psychiatry 44:169-178

Bohn MC (1999) A commentary on glial cell line-derived neurotrophic factor (GDNF): from a glial secreted molecule to gene therapy. Biochem Pharmacol 57:135-142

Caldecott-Hazard S, Morgan DG, DeLeon-Jones F, Overstreet DH, Janowsky D (1991) Clinical and biochemical aspects of depressive disorders. II: transmitter/receptor theories. Synapse 9:251-301

Catterall WA (1999) Interactions of presynaptic $\mathrm{Ca}^{2+}$ channels and snare proteins in neurotransmitter release. In: Rudy B, Seeburg P (eds) Molecular and functional diversity of ion channels and receptors. The New York Academy of Sciences, New York, pp 144-159

Clapham DE, Neer EJ (1993) New roles for G-protein beta gamma-dimers in transmembrane signaling. Nature 365:403-406

Cooper DM, Mons N, Karpen JW (1995) Adenylyl cyclases and the interaction between calcium and cAMP signalling. Nature 374:421-424

Cooper JR, Bloom FE, Roth RH (1996) The biochemical basis of neuropharmacology, 7th edition. Oxford University Press, New York

Cornell-Bell AH, Finkbeiner SM (1991) $\mathrm{Ca}^{2+}$ waves in astrocytes. Cell Calcium 12:185204

Cornell-Bell AH, Finkbeiner SM, Cooper MS, Smith SJ (1990) Glutamate induced calcium waves in cultured astrocytes: long-range glial signaling. Science 247:470-473

Corvalan V, Cole R, de Vellis J, Hagiwara S (1990) Neuronal modulation of calcium channel activity in cultured rat astrocytes. Proc Natl Acad Sci U S A 87:4345-4348 
Danoff SK, Ross CA (1994) The inositol trisphosphate receptor gene family: implications for normal and abnormal brain function. Prog Neuropsychopharmacol Biol Psychiatry $18: 1-16$

Enkvist MOK, McCarthy KD (1992) Activation of protein kinase C blocks astroglial gap junction communication and inhibits the spread of calcium waves. J Neurochem 59:519-526

Furth PA, St Onge L, Boger H, Gruss P, Gossen M, Kistner A, Bujard H, Hennighausen L (1994) Temporal control of gene expression in transgenic mice by a tetracycline-responsive promoter. Proc Natl Acad Sci U S A 91:9302-9306

Galli A, Petersen CI, deBlaquiere M, Blakely RD, DeFelice LJ (1997) Drosophila serotonin transporters have voltage-dependent uptake coupled to a serotonin-gated ion channel. J Neurosci 17:3401-3411

Gegelashvili G, Schousboe A (1997) High affinity glutamate transporters: regulation of expression and activity. Mol Pharmacol 52:6-15

Gilman AG (1989) G proteins and regulation of adenylyl cyclase. JAMA 262:1819-1825

Grady S, Marks MJ, Wonnacott S, Collins AC (1992) Characterization of nicotinic receptor-mediated $\left[{ }^{3} \mathrm{H}\right]$ dopamine release from synaptosomes prepared from mouse striatum. J Neurochem 59:848-856

Grondin R, Gash DM (1998) Glial cell line-derived neurotrophic factor (GDNF): a drug candidate for the treatment of Parkinson's disease. J Neurol 245:35-42

Guldberg HC, Mardsen CA (1975) Catechol-O-methyl transferase: pharmacological aspects and physiological role. Pharmacol Rev 27:135-206

Haga K, Haga T (1992) Activation by G protein $\beta y$ subunits of agonist- or light-dependent phosphorylation of muscarinic acetylcholine receptors and rhodopsin. J Biol Chem 267:2222-2227

Hausdorff WP, Caron MG, Lefkowitz RJ (1990) Turning off the signal: desensitization of $\beta$-adrenergic receptor function. FASEB J 4:2881-2889

Hokin LE, Dixon JF (1993) The phosphoinositide signalling system. I. historical background. II. Effects of lithium on the accumulation of second messenger inositol 1,4,5-trisphosphate in brain cortex slices. Prog Brain Res 98:309-315

Hughes RL (1990) Cyclosporine-related central nervous system toxicity in cardiac transplantation [letter]. N Engl J Med 323:420-421

Inagaki N, Wada H (1994) Histamine and prostanoid receptors on glial cells. Glia 11:102109

Joels M, de Kloet ER (1994) Mineralcorticoid and glucocorticoid receptors in the brain: implications for ion permeability and transmitter systems. Prog Neurobiol 43:1-36

Jursky F, Tamura S, Tamura A, Mandiyan S, Nelson H, Nelson N (1994) Structure, function and brain localization of neurotransmitter transporters. J Exp Biol 196:283-295

Kanai Y, Smith CP, Hediger MA (1994) A new family of neurotransmitter transporters: the high-affinity glutamate transporters. FASEB J 8:1450-1459

Kanner BI, Bendahan A, Pantanowitz S, Su H (1994) The number of amino acid residues in hydrophilic loops connecting transmembrane domains of the GABA transporter GAT-1 is critical for its function. FEBS Lett 356:191-194

Kasai H, Petersen OH (1994) Spatial dynamics of second messengers: IP3 and cAMP as long-range and associative messengers. Trends Neurosci 17:95-101

Kelly RB (1999) An introduction to the nerve terminal. In: Bellen HJ (ed) Neruotransmitter release. Oxford University Press, Oxford, pp 1-33

Kenakin T (1995a) Agonist-receptor efficacy I: mechanisms of efficacy and receptor promiscuity. Trends Pharmacol Sci 16:188-192

Kenakin T (1995b) Agonist-receptor efficacy II: agonist trafficking of receptor signals. Trends Pharmacol Sci 16:232-238

Kilts CD (1994) Recent pharmacologic advances in antidepressant therapy. Am J Med 97(suppl 6A):3S-12S 
Kofman O, Belmaker RH (1993) Ziskind-Somerfeld Research Award 1993. Biochemical, behavioral, and clinical studies of the role of inositol in lithium treatment and depression. Biol Psychiatry 34:839-852

Korn H, Sotelo C, Crepel F (1973) Electronic coupling between neurons in rat lateral vestibular nucleus. Exp Brain Res 16:255-275

Krantz DE, Chaudhry FA, Edwards RH (1999) Neurotransmitter transporters. In: Bellen HJ (ed) Neurotransmitter release. Oxford University Press, Oxford, pp 145-207

Lai J, Bilsky EJ, Rothman RB, Porreca F (1994) Treatment with antisense oligodeoxynucleotide to the opioid delta receptor selectively inhibits delta 2-agonist antinociception. Neuroreport 5:1049-1052

Lapchak PA (1998) A preclinical development strategy designed to optimize the use of glial cell line-derived neurotrophic factor in the treatment of Parkinson's disease. Mov Disord 13(suppl 1):49-54

Lesch KP, Bengel D, Heils A, Sabol SZ, Greenberg BD, Petri S, Benjamin J, Muller CR, Hamer DH, Murphy DL (1996) Association of anxiety-related traits with a polymorphism in the serotonin transporter gene regulatory region [see comments]. Science 274:1527-1531

Lesch KP, Mossner R (1998) Genetically driven variation in serotonin uptake: is there a link to affective spectrum, neurodevelopmental, and neurodegenerative disorders? Biol Psychiatry 44:179-192

Lester HA, Cao Y, Mager S (1996) Listening to neurotransmitter transporters. Neuron 17:807-810

Levitan IB, Kacmarek LK (1997) The neuron: cell and molecular biology, 2nd edition. New York, Oxford University Press

Llinas R, Baker R, Sotelo C (1974) Electronic coupling between neurons in the cat inferior olive. J Neurophysiol 37:560-571

LoTurco JJ, Kriegstein AR (1991) Clusters of coupled neuroblasts in embryonic neocortex. Science 252:563-566

Lovinger DM (1997) Alcohols and neurotransmitter gated ion channels: past, present and future. Naunyn Schmiedebergs Arch Pharmacol 356:267-282

Lucas JJ, Hen R (1995) New players in the 5-HT receptor field: genes and knockouts. Trends Pharmacol Sci 16:246-252

Lyson T, Ermel LD, Belshaw PJ, Alberg DG, Schreiber SL, Victor RG (1993) Cyclosporineand FK506-induced sympathetic activation correlates with calcineurin-mediated inhibition of T-cell signaling. Circ Res 73:596-602

MacDermott AB, Role LW, Siegelbaum SA (1999) Presynaptic ionotropic receptors and the control of transmitter release. Annu Rev Neurosci. 22:443-485

Mannisto PT, Ulmanen I, Lundstrom K, Taskinen J, Tenhunen J, Tilgmann C, Kaakkola S (1992) Characteristics of catechol O-methyl-transferase (COMT) and properties of selective COMT inhibitors. Prog Drug Res 39:291-350

Marshall IC, Taylor CW (1993) Regulation of inositol 1,4,5-trisphosphate receptors. J Exp Biol 184:161-182

Martin DL (1992) Synthesis and release of neuroactive substances by glial cells. Glia 5:81-94

McGeer PL, McGeer EG (1998) Glial cell reactions in neurodegenerative diseases: pathophysiology and therapeutic interventions. Alzheimer Dis Assoc Disord 12(suppl 2):S1-S6

McKnight GS (1991) Cyclic AMP second messenger systems. Curr Opin Cell Biol 3:213217

Melcangi RC, Magnaghi V, Martini L (1999) Steroid metabolism and effects in central and peripheral glial cells. J Neurobiol 40:471-483

Melikian HE, Ramamoorthy S, Tate CG, Blakely RD (1996) Inability to N-glycosylate the human norepinephrine transporter reduces protein stability, surface trafficking, and transport activity but not ligand recognition. Mol Pharmacol 50:266-276 
Nalepa I (1994) The effect of psychotropic drugs on the interaction of protein kinase C with second messenger systems in the rat cerebral cortex. Pol J Pharmacol 46:1-14

Narahashi T, Aistrup GL, Marszalec W, Nagata K (1999) Neuronal nicotinic acetylcholine receptors: a new target site of ethanol. Neurochem Int 35:131-141

Nelson N (1998) The family of Na+/Cl- neurotransmitter transporters. J Neurochem $71: 1785-1803$

Nishizuka Y (1995) Protein kinase C and lipid signaling for sustained cellular responses. FASEB J 9:484-496

Oswald I, Brezinova V, Dunleavy DLF (1972) On the slowness of action of tricyclic antidepressant drugs. Br J Psychiatry 120:673-677

Otero GC, Merrill JE (1994) Cytokine receptors on glial cells. Glia 11:117-128

Parthasarathy L, Vadnal RE, Parthasarathy R, Devi CS (1994) Biochemical and molecular properties of lithium-sensitive myo-inositol monophosphatase. Life Sci 54:1127-1142

Paul IA, Nowak G, Layer RT, Popik P, Skolnick P (1994) Adaptation of the N-methyl-Daspartate receptor complex following chronic antidepressant treatments. J Pharmacol Exp Ther 269:95-102

Pitcher JA, Inglese J, Higgins JB, Arriza JL, Casey PJ, Kim C, Benovic JL, Kwatra MM, Caron MG, Lefkowitz RJ (1992) Role of beta gamma subunits of G proteins in targeting the beta-adrenergic receptor kinase to membrane-bound receptors. Science 257:1264-1267

Poitry-Yamate CL, Poitry S, Tsacopoulos M (1995) Lactate released by Muller glial cells is metabolized by photoreceptors from mammalian retina. J Neurosci 15:5179-5191

Premont RT, Inglese J, Lefkowitz RJ (1995) Protein kinases that phosphorylate activated G protein-coupled receptors. FASEB J 9:175-182

Rahamimoff R, Butkevich A, Duridanova D, Ahdut R, Harari E, Kachalsky SG (1999) Multitude of ion channels in the regulation of transmitter release. Philos Trans R Soc Lond B Biol Sci 354:281-288

Raivich G, Jones LL, Werner A, Bluthmann H, Doetschmann T, Kreutzberg GW (1999) Molecular signals for glial activation: pro- and anti-inflammatory cytokines in the injured brain. Acta Neurochir Suppl (Wien) 73:21-30

Ransom BR, Sontheimer H (1992) The neurophysiology of glial cells. J Clin Neurophysiol 9:224-251

Rens-Domiao S, Hamm HE (1995) Structural and functional relationships of heterotrimeric G-proteins. FASEB J 9:1059-1066

Robinson SR, Hampson E, Munro MN, Vaney DI (1993) Unidirectional coupling of gap junctions between neuroglia. Science 262:1072-1074

Ronde P, Nichols RA (1998) High calcium permeability of serotonin 5-HT3 receptors on presynaptic nerve terminals from rat striatum. J Neurochem 70:1094-1103

Saarma M, Sariola H (1999) Other neurotrophic factors: glial cell line-derived neurotrophic factor (GDNF). Microsc Res Tech 45:292-302

Saudou F, Amara DA, Dierich A, LeMeur M, Ramboz S, Segu L, Buhot MC, Hen R (1994) Enhanced aggressive behavior in mice lacking 5-HT1B receptor. Science 265:18751878

Schlag BD, Vondrasek JR, Munir M, Kalandadze A, Zelenaia OA, Rothstein JD, Robinson MB (1998) Regulation of the glial Na+-dependent glutamate transporters by cyclic AMP analogs and neurons. Mol Pharmacol 53:355-369

Shank RP, William JB, Charles WA (1989) Glutamine and 2-oxoglutarate as metabolic precursors of the transmitter pools of glutamate and GABA: correlation of regional uptake by rat brain synaptosomes. Neurochem Res 16:29-34

Shepard GM (1994) Neurobiology, 2nd edition. New York, Oxford University Press

Shinohara K, Hiruma H, Funabashi T, Kimura F (2000) GABAergic modulation of gap junction communication in slice cultures of the rat suprachiasmatic nucleus. Neuroscience 96:591-596 
Silvia CP, King GR, Lee TH, Xue ZY, Caron MG, Ellinwood EH (1994) Intranigral administration of D2 dopamine receptor antisense oligodeoxynucleotides establishes a role for nigrostriatal D2 autoreceptors in the motor actions of cocaine. Mol Pharmacol 46:51-57

Singer TP, Ramsay RR (1995) Monoamine oxidases: old friends hold many surprises. FASEB J 9:605-610

Sontheimer H (1994) Voltage dependent ion channels in glial cells. Glia 11:156-172

Standifer KM, Chien CC, Wahlestedt C, Brown GP, Pasternak GW (1994) Selective loss of delta opioid analgesia and binding by antisense oligodeoxynucleotides to a delta opioid receptor. Neuron 12:805-810

Stephens DN, Kehr W, Duka T (1986) Anxiolytic and anxiogenic $\beta$-carbolines: tools for the study of anxiety mechanisms. In: Biggio G, Costa E (eds) GABAergic transmission and anxiety. Raven, New York, pp 91-106

Swanson RA, Liu J, Miller JW, Rothstein JD, Farrell K, Stein BA, Longuemare MC (1997) Neuronal regulation of glutamate transporter subtype expression in astrocytes. J Neurosci 17:932-940

Tallman JF, Cassela JV, White G, Gallager DW (1999) GABA receptors: diversity and its implications for CNS disease. The Neuroscientist 5:351-361

Tecott LH, Sun LM, Akana SF, Strack AM, Lowenstein DH, Dallman MF, Julius D (1995) Eating disorder and epilepsy in mice lacking 5-HT2c serotonin receptors. Nature 374:542-546

Thiel G. (1995) Recent breakthroughs in neurotransmitter release: paradigm for regulated exocytosis? News in Physiological Science 10:42-46

Thomas KR, Capecchi MR (1990) Targeted disruption of the murine int-1 proto-oncogene resulting in severe abnormalities in midbrain and cerebellar development. Nature 346:847-850

Tsacopoulos M, Magistretti PJ (1996) Metabolic coupling between glia and neurons. J Neurosci 16:877-885

Vardimon L, Ben-Dror I, Avisar N, Oren A, Shiftan L (1999) Glucocorticoid control of glial gene expression. J Neurobiol 40:513-527

Wahlestedt C, Pich EM, Koob GF, Yee F, Heilig M (1993) Modulation of anxiety and neuropeptide Y-Y1 receptors by antisense oligodeoxynucleotides. Science 259:528-531

Walsh DA, Van Patten SM (1994) Multiple pathway signal transduction by the cAMP-dependent protein kinase. FASEB J 8:1227-1236

Wartiovaara K, Hytonen M, Vuori M, Paulin L, Rinne J, Sariola H (1998) Mutation analysis of the glial cell line-derived neurotrophic factor gene in Parkinson's disease. Exp Neurol 152:307-309

Watkins SS, Epping-Jordan MP, Koob GF, Markou A. (1999) Blockade of nicotine self-administration with nicotinic antagonists in rats. Pharmacol Biochem Behav 62:743751

Wolfe BB, Harden TK, Sporn JR, Molinoff PB (1978) Presynaptic modulation of beta adrenergic receptors in rat cerebral cortex after treatment with antidepressants. J Pharmacol Exp Ther 207:446-457

Wonnacott S (1997) Presynaptic nicotinic ACh receptors. Trends in Neuroscience 20:9298

Yakel JL (1997) Calcineurin regulation of synaptic function: from ion channels to transmitter release and gene transcription. Trends Pharmacol Sci. 18:124-134

Yeomans J, Baptista M (1997) Both nicotinic and muscarinic receptors in ventral tegmental area contribute to brain-stimulation reward. Pharmacol Biochem Behav 57:915921

Yudosky SC, Hales RE (eds) (2002) The American Psychiatric Press Textbook of Neuropsychiatry, 4th edn. American Psychiatric Publishing. Washington, DC, pp 11231147 
Zahs KR (1998) Heterotypic coupling between glial cells of the mammalian central nervous system. Glia 24:85-96

Zhang B, Ramaswami M (1999) Synaptic vesicle endocytosis and recycling. In: Bellen HJ (ed) Neurotransmitter release. Oxford University Press, Oxford, pp 389-431

Zhou LW, Zhang SP, Qin ZH, Weiss B (1994) In vivo administration of an oligodeoxynucleotide antisense to the D2 dopamine receptor messenger RNA inhibits D2 dopamine receptor-mediated behavior and the expression of D2 dopamine receptors in mouse striatum. J Pharmacol Exp Ther 268:1015-1023 
